International Journal of

BioScience and Applications

\title{
Development and Evaluation of Structured Nursing Process Education Program for Nursing Students : Case study of Burn Patient Pain Management -Structured Kimmy Program ver.1.0(SKP 1.0)-
}

\author{
Hyun- Gu Park ${ }^{1}$, Hack-Sun Kim ${ }^{1}$, Ja-Ok Kim ${ }^{1}$, Su- Hyun Kim², \\ Myunghee $\mathrm{Jun}^{3}$, and Ja-Sook Kim ${ }^{4 *}$ \\ ${ }^{1}$ Department of Nursing, Wonkwang Health Science university, Iksan, Republic of Korea \\ ${ }^{2}$ Department of Nursing, Nambu University, Gwangju, Republic of Korea \\ ${ }^{3}$ Department of Nursing and Health Studies, University of Wisconsin-Green Bay, USA \\ ${ }^{4}$ Department of Nursing , Donggang University, Gwangju, Republic of Korea
}

\begin{abstract}
Background/Objectives: This study aims to apply a structured nursing process education program and test the effectiveness of nursing college students in order to effectively conduct case studies in their first clinical practice. Methods/Statistical analysis: This study is a methodological study to develop a structured nursing process education program suitable for the competency of first time nursing clinical practice college students for the first time through literature review and a group of experts. Findings: The results of case studies of clinical practice students by applying the structured nursing process education program are as follows. In the first clinical practice, anxiety about the patient case study nursing process was reduced. It strengthened the learning ability of clinical practice students. The application of the structured nursing process education program increased satisfaction with teaching methods. Through structured nursing process education, quantitative studies are conducted to determine whether the academic competency of clinical practice students has increased. Improvements/Applications: It is suggested that the structured nursing process program be modified to be used in various nursing area.
\end{abstract}

\section{Index Terms}

Structured nursing process education program, Nursing student, Clinical practice, Case study, Methodological study

\author{
Corresponding author : Ja-Sook Kim \\ jskim-98@hanmail.net \\ - Manuscript received January 1, 2020. \\ - Revised February 10, 2020 ; Accepted March 2, 2020. \\ - Date of publication March 30, 2020. \\ (c) The Academic Society of Convergence Science Inc. \\ 2619-8363 (C) 2020 IJBSA. Personal use is permitted, but republication/redistribution requires IJBSA permission.
}




\section{INTRODUCTION}

Today healthcare systems demand that new graduates and professionals be prepared to care for acutely ill and complex patients in diverse settings. Healthcare educators are searching for ways to better ready students for complexities and challenges of clinical practice settings. Educators suggest the new approaches to current pedagogical methodologies in healthcare education.

The basic concepts of nursing are nursing, human, health, and environment. Holistic nursing is based on considering all aspects of the subject that affect human basic needs in health and disease. The goal of nursing is to help maintain independence and continue your potential development. The primary focus of nursing is the human. Includes the physical, mental, social, and spiritual realms of a person[1]. Nursing is the process of finding and caring for a patient's problem. In the nursing process, nurses take care of patients based on their knowledge. Therefore, it is important for nursing college students to learn the nursing process in clinical practice.

The nursing process consists of assessment, diagnosis, planning, intervention, and evaluation. Students learn the nursing process through case studies in clinical practice. Nursing assessment is the process of collecting data. Nursing diagnosis is problem finding. The nursing plan determines priorities and sets short-term and long-term goals. Nursing intervention is direct or indirect nursing practice to achieve a goal. Nursing evaluate the patient's goals and achievement of expected results[2-3]. Clinical practice is an important learning opportunity to learn the knowledge, skills, and attitudes of nursing through the actual field[4]. Seeing the patient's case in clinical practice is essential to understanding the nursing process. However, nursing college students who have gone through clinical practice for the first time have difficulty applying the nursing course. For nursing college students, the first clinical practice is a serious stress in itself[5].

Therefore, systematic learning is necessary while adapting to a new educational environment called clinical practice through a structured nursing process education program. This study aims to apply a structured nursing process education program (Structure Kimmy Program version 1.0, SKP) and test the effectiveness of nursing college students in order to effectively conduct case studies in their first clinical practice.

\section{MATERIALS AND METHOD}

\section{A. Study Design}

This study is a methodological study to develop a structured nursing process education program suitable for the competency of first time nursing clinical practice college students for the first time through literature review and a group of experts.

\section{B. Development Process}

The structured nursing process education program development(Structure Kimmy Program version 1.0, SKP) is as follows.
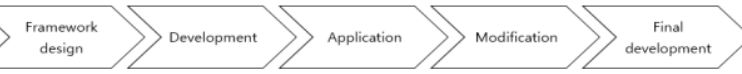

Fig. 1. DEVELOPMENT PROCESS OF STRUCTURED NURSING PROCESS EDUCATION PROGRAM(SKP Ver.1.0)

1) Conceptual framework design stage of nursing process : A conceptual framework for nursing courses is established by examining textbooks of nursing and domestic and foreign literature[1-4].

2) Development of preliminary program and content validation of expert group : Content validity verification was based on research conducted by a group of 3-10 experts[6]. The content validity was verified by consisting meeting 5 times of four professors in the nursing department and two nurses with over 30 years of nursing experience. In the content validity verification, the CVI for each item was $0.8-1$.

3) Application of preliminary program : It was applied to the 3rd grade of nursing college for the first clinical practice nursing course.

4) Complementary steps to correct preliminary program : After the clinical practice was completed, feedback on the structured nursing process program was received and corrected.

5) Constructed structured nursing process education program version 1.0: The detailed contents of the structured nursing process education program version 1.0(Structure Kimmy Program version 1.0, SKP) are as follows[2-3](Figure 2).

(1) Selection of nursing process cases

We choose a disease group that is very popular with Koreans. Consider gender and age. Understand the pathophysiology of the disease(Table 1).

(2) Nursing assessment

All data related to the patient are important. Make a list to compare patients based on textbooks. Collect objective and subjective data sufficiently and quickly. Observe patient changes over time. To have an integrated understanding of patients. 
Table 1. CASE ABOUT BURN PATIENT

1) General characteristics

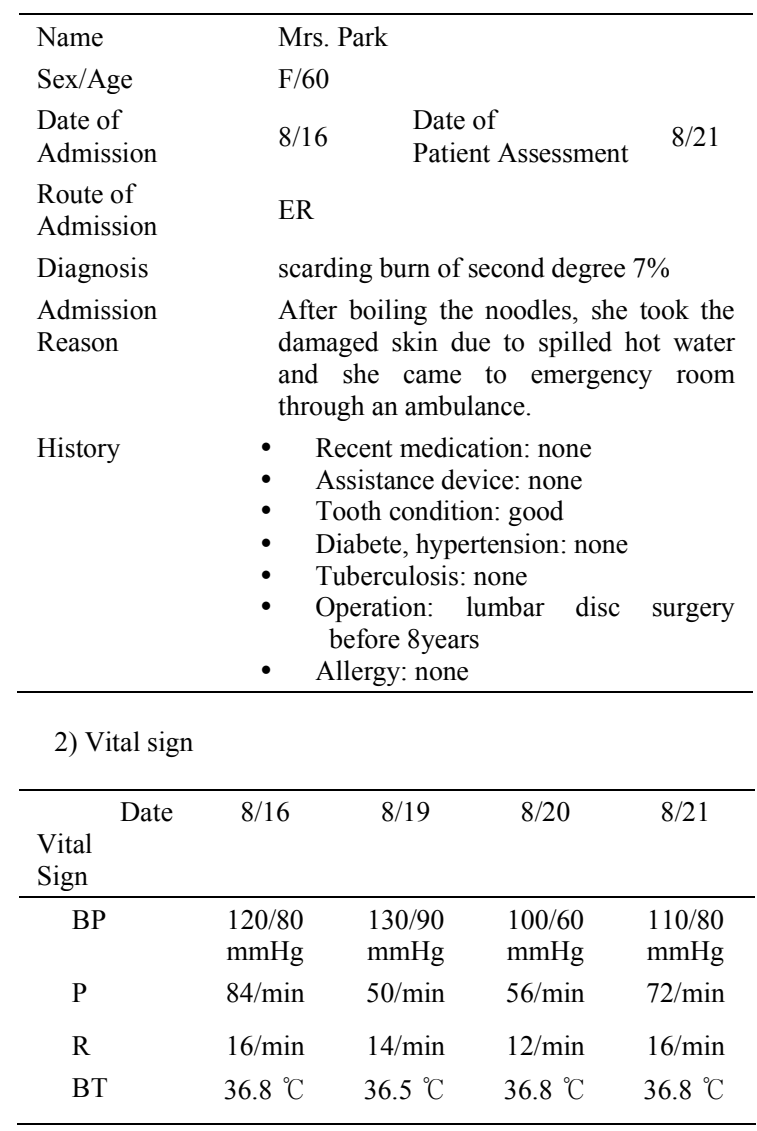

3) Blood examination

\begin{tabular}{cll}
\hline $\begin{array}{l}\text { Laboratory } \\
\text { data }\end{array}$ & \multicolumn{1}{c}{ Date } & \multicolumn{1}{c}{$\begin{array}{l}\text { Normal } \\
\text { Range }\end{array}$} \\
\hline $\mathrm{WBC}$ & $6.5210^{*} 3 \mathrm{~mm}^{3}$ & $4 \sim 1010 * 3 \mathrm{~mm}^{3}$ \\
$\mathrm{Hb}$ & 14.0 & $12 \sim 15.9$ \\
$\mathrm{CRP}$ & $0.34 \mathrm{mg} / \mathrm{dL}$ & $0 \sim 5 \mathrm{mg} / \mathrm{dL}$ \\
Sodium & 143 & $136 \sim 145$ \\
Potassium & 4.0 & $3.5 \sim 5.0$ \\
\hline
\end{tabular}

4) Chest PA result: non-specific

\section{(3) Nursing diagnosis}

Clarify the basis for nursing diagnosis.

(4) Nursing plan

The goal is an achievable level. Determine if nursing diagnosis can be resolved when the nursing goal is reached.

(5) Nursing intervention

Nursing interventions are performed clearly. Make sure to make an intervention table and use it for nursing intervention. The nursing intervention table makes it possible to grasp the situation at a glance. There are educational goals when conducting nursing education to patients. You should not entrust your caregiver to nursing interventions.

(6) Nursing evaluation

Determine whether short-term and long-term goals are achieved. If the nursing goals are not met, record the exact reason and provide feedback.

(7) Report writing

Case studies are qualitative. Describe your opinion convincingly and logically.

(8) Writing references

We follow the method of writing a representative journal of nursing.

(9) Feedback and revision

We got the feedback through structured questionnaire.

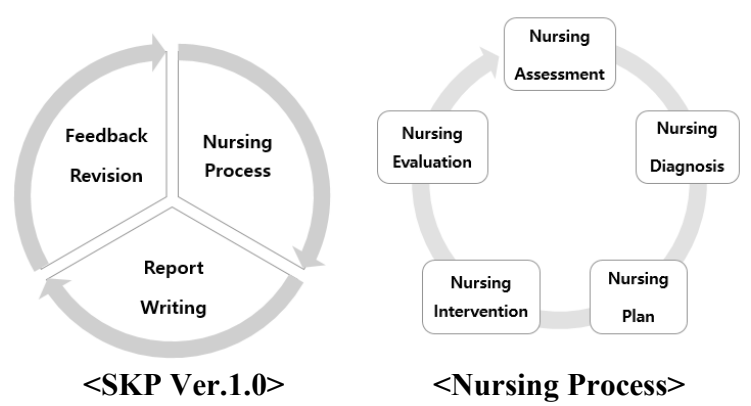

Fig. 2. Comprehensive flow of structured nursing process education program (SKP Ver.1.0)

\section{RESULTS AND DISCUSSION}

This is the result of a case study on burn patient pain management in clinically trained students who applied the Structured Nursing process Education Program (Structure Kimmy Program version 1.0, SKP). According to the insurance claim data from 2013 to 2017 in the Health Care Big Data Open System of the Korea Health Insurance Review and Assessment Service, the number of burn patients in Korea is about 2.7 million in 5 years[7]. According to the classification of burns, burns of less than $9 \%$ of body surface area increased from 490,000 to 520,000 . The incidence of moderate burns over $37 \%$ of body surface area was reduced. In men, the area of burn injury has increased[7]. First-degree burns are caused by prolonged exposure to direct sunlight or instantaneous contact or exposure to high heat. It is a hot water burn and a light flame burn. Most of them form blisters. Second-degree burns are accompanied by swelling of the subcutaneous tissue and severe pain. Third-degree burns are a condition in which damage to the epidermis, dermis, and subcutaneous fat layers of the skin is spread, forming a thick skin[8]. Second-degree burns can heal within 10 to 14 days. Superficial second-degree burns that cause strong pain due to stimulation contact or temperature changes due to exposure to the nerve endings are 
cured within 3 to 6 weeks. However, deeper invasion into the dermis layer destroys the nerve endings, resulting in a second degree of deep burns with weak pain[9].

This study case was conducted for a 60 -year-old woman who visited the emergency room with a burn. Nursing diagnosis is pain associated with skin damage. For the nursing intervention, drug therapy, dressing therapy, cold therapy, and image therapy were applied. In this case study, a nursing student in clinical practice utilized a structured nursing process education program(Structure Kimmy Program version 1.0, SKP) at $\mathrm{W}$ University Hospital located in I city for two weeks from August 19 to August 30, 2019.

The result of the nurse assessment is as follows. On August 16, 2019, while boiled noodles, boiled noodles spilled water and were hospitalized through the emergency room. There were no medications currently being used. She had a history of lumbar disc surgery in 2011 eight years ago. The position and range of the burn are a $20 \times 15 \mathrm{~cm} \mathrm{2-degree}$ superficial image on the right thigh and a $20 \times 20 \mathrm{~cm}$ 2-degree superficial image on the left thigh. Nursing diagnosis is an infection risk associated with skin damage and pain associated with skin damage. The pain complaint was particularly severe and the patient was very uncomfortable, so look for the cause of the pain in order to promote peace. Subjective data, "The legs are hot sensation", "It is painful." As an objective data, the NRS pain score was 5 points. Redness and edema were observed. The nursing goal is to select what nursing students can do. Use it as a standard for nursing evaluation. The long-term goal is that patients can live their daily lives without pain until discharge. The short-term goal is that patients have an NRS pain score of 3 or less within 5 days.

The result of the nurse intervention is as follows. Make a nursing intervention table. Encouraging the patient, By listening to the patient's story, the subject's mind is stabilized. Emotional emotion is a major factor in perception of pain. Image therapy that promotes positive emotions and energy is effective for pain. If you have a sense of heat, use a paper fan. By avoiding direct skin irritation to sensitive skin such as burns, it smoothes ventilation and lowers heat, thereby reducing pain. The most effective thing in pain management was encouraging me. Patient satisfaction was high. Psychological support is very important in pain management. For burn patients, music therapy was effective in alleviating patient anxiety[10]. Paper fanning was ineffective. It is difficult to fan regularly and consistently. It is difficult to continue. There is a need for research to reduce the heat of pain by using an electric fan. and drug-induced pain control and dressing is performed by a doctor's order. Pain control in burn patients is effective by drugs and non-pharmacological methods[11](Table 2).

Table 2. NURSING PROCESS FOR BURN PATIENT

\begin{tabular}{|c|c|}
\hline $\begin{array}{l}\text { Nursing } \\
\text { Diagnosis }\end{array}$ & Pain associated with skin damage \\
\hline $\begin{array}{l}\text { Assessment } \\
\text { Data }\end{array}$ & $\begin{array}{l}\text { - Subjective data } \\
\text { "I'm so hot and sick." } \\
\text { - Objective data } \\
\text { Checked NRS score } 5 \text { point. } \\
\text { Observed redness. } \\
\text { Observed swelling. }\end{array}$ \\
\hline $\begin{array}{l}\text { Nursing } \\
\text { Plan }\end{array}$ & $\begin{array}{l}\text {-Long Term Target: She can do well without } \\
\text { pain upon discharge. } \\
\text {-Short Term Target : She can give the NRS } \\
\text { score below } 3 \text { point within } 5 \text { days. }\end{array}$ \\
\hline \multirow[t]{8}{*}{$\begin{array}{l}\text { Nursing } \\
\text { Intervention }\end{array}$} & $\begin{array}{l}1-^{1} \text {. Injection Hartman solution fluid } 500 \mathrm{ml} \\
\text { mixed Fentanyl } 0.1 \mathrm{mg} \text { if patient tells unbearable } \\
\text { pain }\end{array}$ \\
\hline & $8 / 26$ \\
\hline & Fentanyl $0.1 \mathrm{mg}$ \\
\hline & NRS score \\
\hline & $\begin{array}{l}\text { Y: injected, N: not injected) } \\
2-^{2} \text {. Applied the foam dressing on damaged skin }\end{array}$ \\
\hline & $8 / 28$ \\
\hline & Foam dressing \\
\hline & $\begin{array}{l}\text { (O: applied dressing) } \\
3-{ }^{3} . \text { Removed elastic bandage wrapped leg. } \\
4-{ }^{4} \text {. Offered hand-fan if she feels heat. }\end{array}$ \\
\hline $\begin{array}{l}\text { Nursing } \\
\text { Evaluation }\end{array}$ & $\begin{array}{l}\text {-Long Term Target: unachieved } \\
\text {-Short Term Target: achieved } \\
\text {-Opinion: The reason long term target was } \\
\text { unachieved is that the patient is still in hospital. } \\
\text { Follow-up need. }\end{array}$ \\
\hline
\end{tabular}

The structured nursing process education program(Structure Kimmy Program version 1.0, SKP) helps students to think and practice systematically. In the future it needs to develop the web-based program about these education program[12-14]. Web-based nursing education program exist in a variety of different institutions[1215]. New and emerging technology directly impacts how educators facilitate distance education and how it might affect future web-based learning environment[12,15-16]. Nursing educators need to rethink not only what explains for academic achievement, but also what evaluates for classroom and clinical learning experience.

In particular, if this education program is developed by web-based setting, it's very useful to educate not only nurse and but also nursing assistants[17-18]. Due to the lack of nursing personnel, it is necessary to focus on the education of nursing assistants through the systematic and scientific methods[18,19]. And improve access to education by using LMS[20]. 


\section{CONCLUSION}

The results of case studies of clinical practice students by applying the structured nursing process education program(Structure Kimmy Program version 1.0, SKP) are as follows. In the first clinical practice, students' anxiety about the patient case study of nursing process was reduced. It strengthened students' learning ability in clinical practice setting. The first clinical practice aroused interest in the nursing process. In the first clinical practice, a structured nursing process education program was applied to generate interest in nursing. The patient's nursing care needs can be easily identified through the intervention table. The application of the Structured Nursing process Education Program (Structure Kimmy Program version 1.0, SKP) increased satisfaction with teaching methods. Through structured nursing process education, quantitative studies are conducted to determine whether the academic competency of clinical practice students has increased. It is suggested that the structured nursing process program be modified to be used in other occupations in the nursing area.

\section{REFERENCES}

[1] Yang, S. H. et al(2020). Fundamental Nursing I Seoul: Hyunmoonsa.

[2] Kim, H. S. \& Kim, J. S.(2019). Understanding Adult Nursing for Chinese Students. Seoul:Eunhaksa.

[3] Kim, J. S., Ji, H. L., \& Kim, J. O.(2020). Core Fundamental Nursing Guidebook I, Seoul:Eunhaksa.

[4] Lee, H. J.(2014). Image of Nurse Perceived by Nursing Student Before and After Their First Clinical Practice, Journal of East-West Nursing Research, 20(2), 129-135. DOI: 10.14370/jewnr.2014.20.2.129

[5] J. I. Kim and J. S. Lee.(2011). Effects of clinical training on stress, anxiety and changes in autonomic nervous system in nursing students. Journal of Korean Biological Nursing Science, 13(2), 102-108.

[6] Lynn, M. R.(1986). Determination and quantification of content validity. Nursing Research, 35, 382-385.

[7] Health care big data open system(2019). National Interest Disease Statistics. Retrieved from http://opendata.hira.or.kr/op/opc/olapMfrnIntrs InsInfo.do

[8] Hallym University Han River Sacred Heart Hospital.(2019). Health Encyclopedia, Treatment and Prevention of Burns. Retrieved

From https://hangang.hallym.or.kr/hallymuniv_sub. asp?left menu $=$ left health\&screen $=$ ptm $802 \& \bar{H}$ ealth $\mathrm{No}=92 \&$ search text $=\% \mathrm{C} 8 \% \mathrm{AD} \% \mathrm{BB} \% \mathrm{~F} 3 \mathrm{Aa} 04$

[9] Hwang, O. N.(2018). Adult Nursing. Seoul: Hyunmoonsa.

[10] Kim, J. H.(1999). An Effect of Guided Imagery on Pain. Korean Academic Society of Nursing Education, 5(1), 20-38.
[11] Patel, M. (2016). Pain Management of the Burn Patient. Topics in Pain Management, 32(5), 1-8. DOI:10.1097/01.tpm.0000510694.67407.74

[12] Lee, E., \& Noh, H. K. (2015). The Effects of a WebBased Nursing Process Documentation Program on Stress and Anxiety of Nursing Students in South Korea. International Journal of Nursing Knowledge, 27(1), 35-42. DOI:10.1111/2047-3095.12072

[13] Kim, H. S., \& Jung, H. S. (2016). Development and Effectiveness of Web Based Learning Nursing Process Program on Linked NANDA, NOC and NIC. International Journal of Multimedia and Ubiquitous Engineering, 11(4), 207-214. DOI:10.14257/ijmue.2016.11.4.21

[14] Batchelor-Murphy, M., Amella, E. J., Zapka, J., Mueller, M., \& Beck, C. (2015). Feasibility of a webbased dementia feeding skills training program for nursing home staff. Geriatric Nursing, 36(3), 212 218.

DOI:10.1016/j.gerinurse.2015.02.003

[15] Yuksekdag, B. B. (n.d.). The Importance of Mobile Augmented Reality in Online Nursing Education. Nursing Education, Administration, and Informatics, 111-125.

DOI: 10.4018/978-1-5225-5490-5.ch008

[16] Rees, S., Moloney, C., \& Farley, H. (2015). Mobile Learning Initiatives in Nursing Education. Handbook of Mobile Teaching and Learning, 275-289. DOI: $10.1007 / 978-3-642-54146-9 \_37$

[17] Wingo, N. P., Peters, G. B., Ivankova, N. V., \& Gurley, D. K. (2016). Benefits and Challenges of Teaching Nursing Online: Exploring Perspectives of Different Stakeholders. Journal of Nursing Education, 55(8), 433-440. DOI: $10.3928 / 01484834-20160715-03$

[18] Arvidson, S. (2018). Nursing Education: Challenges Exist Globally for the Diverse Learner. Juniper Online Journal of Case Studies, 6(1). DOI: 10.19080/jojcs.2018.06.555678

[19] Algoso, M., Ramjan, L., East, L., \& Paters, K.(2019). An exploration of undergraduate nursing assistant employment in aged care and its value to undergraduate nursing education. Nurse Education Today, 82, 32-26. DOI: $10.1016 /$ j.nedt.2019.08.005

[20] Hector John T. Manaligod, Rogelio V. del Cano, \&Jelica R. Enriquez (2019). Adoption Determinants of a Learning Management System in a Higher Education Institution: A Faculty Perspective. International Journal of Advanced Science and Convergence, 1(1), 7-22. DOI: 10.22662/IJASC.2019.1.1.007. 